\title{
ALINHAMENTO DOS PROJETOS DE TI AO PLANEJAMENTO ESTRATÉGICO: UM ESTUDO DE CASO DE UNIVERSIDADE PRIVADA BRASILEIRA PERTENCENTE A UM GRUPO AMERICANO
}

\author{
V. A. SILVA* e C. M. C. MENDONÇA** \\ Universidade Potiguar - UnP, Universidade Federal do Amapá - UNIFAP/NEGEO \\ Branco2@gmail.com*, cmarcio@gmail.com
}

Artigo submetido em novembro/2015 e aceito em dezembro/2015

DOI: 10.15628/empiricabr.2015.3745

\section{RESUMO}

O objetivo deste trabalho foi descrever o processo de alinhamento estratégico dos projetos de TI de uma Universidade privada pertencente a um grupo Americano. Demonstrou como ocorre a classificação e priorização dos projetos em relação aos objetivos estratégicos da instituição. Foi desenvolvida uma pesquisa exploratória/descritiva, com abordagem de forma qualitativa, método de estudo de caso, técnica de coleta de dados documental e entrevistas com questões semiestruturadas. Com os resultados obtidos através do estudo de caso, concluiu-se que a aplicação do método proporciona uma gestão mais efetiva dos recursos de TI, mantendo o alinhamento com os objetivos estratégicos das áreas organizacionais. A organização estudada mostrou maturidade no uso de ferramentas de gestão, principalmente pelo o uso do BSC, que possibilita, através de seus conceitos e métodos, uma visão clara das estratégias, objetivos e metas empresariais, esclarecendo e estabelecendo consensos.

PALAVRAS-CHAVE: Gestão de Projetos de TI, Maturidade de Projetos, Alinhamento Estratégico de Negócio e TI, Balanced Scorecard

\section{ALIGNMENT OF THE STRATEGIC PLANNING IT PROJECT: A STUDY OF PRIVATE UNIVERSITY CASE BRAZILIAN BELONGING TO AN AMERICAN GROUP}

\begin{abstract}
The objective of this study was to describe the strategic alignment of the IT projects of a private university owned by an American group. Demonstrated how does the classification and prioritization of projects in relation to the strategic objectives of the institution. An exploratory / descriptive study was conducted with qualitative approach, method of case study, document data collection technique and interviews with semistructured questions. With the results obtained through the case study, it was concluded that the method of
\end{abstract}

application provides a more effective management of IT resources while maintaining alignment with the strategic objectives of organizational areas. The organization studied showed maturity in the use of management tools, mainly by the use of BSC, which allows, through its concepts and methods, a clear vision of the strategies, objectives and business goals, clarifying and establishing consensus.

KEYWORDS: IT Project Management, Project Maturity, Strategic Alignment of Business and IT, Balanced Scorecard. 


\section{INTRODUÇÃO}

O crescimento do uso da gestão de projetos pode ser medido pelo número de certificações de profissionais PMP em todo o mundo: de 27.052 em 2000 para mais de 260.000 em 2008 (IETEC, 2013). Isto demonstra uma melhoria considerável na eficiência dos processos de planejamento, execução, administração e avaliação dos projetos. As práticas de gestão de recursos, tempo e custos estão constantemente melhorando, tornando-se mais precisas e científicas. Essa tendência tem como marco inicial a fundação do Project Management Institute (PMI), em 1969, e a subsequente publicação do Project Management Body of Knowledge (PMBOK), atualmente em sua quinta edição (PMI, 2013).

Mesmo com o evidente aumento da utilização do gerenciamento de projetos por parte das empresas, ainda se observam altos índices de falhas em projetos (Forman apud Rad e Raghavan, 2000). Crawford (2000) justifica essa ineficácia pela falta de processos adequados e padronizados de gerenciamento. Já Mintzberg (1998), afirma que existe um gap entre as fases de elaboração e implementação da estratégica corporativa, e que isso deve ser melhor trabalhado por estrategistas e gerentes de projeto para garantir que estejam efetivamente bem alinhados com os objetivos e metas estratégicas das organizações.

O Escritório de Gerenciamento de Projetos (EGP) surge então como a unidade organizacional responsável pela correção desses problemas e, adicionalmente, pela divulgação das práticas de gerenciamento de projetos para toda a organização, possibilitando a diminuição dos índices de falhas e garantindo que os projetos mais importantes para a organização sejam tratados de forma prioritária.

Nesse contexto, a Tecnologia da Informação (TI) tem um papel fundamental e estratégico para agregar valor aos produtos e serviços das organizações. É necessário que as organizações tenham o planejamento empresarial e de TI integrados, coerentes e com sinergia, onde as estratégias empresariais e de TI estejam plenamente alinhadas.

O objetivo deste trabalho é descrever o processo de alinhamento estratégico dos projetos de TI de uma Universidade Privada da região Nordeste, onde será apresentado como ocorre a classificação e priorização dos projetos em relação aos objetivos estratégicos da instituição, como instrumento de apoio ao gerenciamento de projetos e de implementação das estratégias organizacionais.

A relevância do tema pode ser observada no crescente número de estudos acadêmicos e na prioridade que as organizações têm dado ao assunto.

\section{FUNDAMENTAÇÃO TEÓRICA}

\subsection{MERCADO DO ENSINO SUPERIOR}

O setor de ensino superior no Brasil tem passado por grandes mudanças desde o início dos anos 90. Na última década, em razão do ambiente sócio-político-econômico, a área de educação de nível superior teve um grande crescimento, principalmente de instituições privadas, e isso se deve à facilidade de abertura de Instituições de Ensino Superior (IES), desde as mudanças da última reforma da educação em 1996, o que transformou o ambiente de ensino superior no país mais concorrido (MENDONÇA, 2009).

De lá pra cá houve um grande aumento do número de alunos matriculados neste segmento de educação, especialmente na rede privada, em grande parte apoiadas por políticas públicas do Governo Federal como o ProUni (Programa Universidade para Todos), FIES (Programa de 
Financiamento Estudantil) e outros programas educacionais praticados pelos municípios brasileiros.

Dados do Ministério da Educação e Cultura (MEC) demonstram que o mercado de Instituições de Ensino Superior no país vem realmente tendo esse crescimento nos últimos anos, que é maior do que muitos segmentos da economia. Por consequência do aumento no número de IES, as vagas ofertadas acompanharam o crescimento: nas IES públicas de 2007 a 2012 o aumento foi de mais de $47 \%$; enquanto que nas IES privadas, cerca de $10 \%$. Nas IES privadas, tivemos um aumento de cerca de $14 \%$ no número de matriculados (BRASIL, 2013).

A reforma da educação em 1996 ocasionou um aumento das IES privadas e o plano de apoio a reestruturação e expansão das Universidades Federais (REUNI), tem gerado um aumento de vagas e de novas IES públicas, tornando o ambiente do ensino superior privado mais acirrado (MENDONÇA, 2009). Mas o ambiente do ensino superior privado continua em expansão. Muitas novas Instituições de Ensino Superior (IES) têm surgido. O Governo Federal aprimorou seu sistema de avaliação e alguns dos participantes do mercado profissionalizaram sua gestão, até mesmo abrindo capital na Bolsa de Valores de São Paulo (Bovespa) e realizando aquisições de outras IES como novos investimentos por todo o País.

Entretanto, sabemos que a realidade empresarial enfrenta dificuldades no alinhamento e na sinergia de seus planejamentos quando envolvem e/ou necessitam da TI e de seus recursos. Essa atividade é um desafio constante e vem consumindo muito dinheiro das organizações que se preocupam com essa questão, em que os recursos investidos em $\mathrm{TI}$ nem sempre dão o retorno esperado aos seus investidores.

\subsection{ALINHAMENTO ESTRATÉGICO}

A estratégia remonta da Grécia Antiga. O termo "estratégia" originou-se da expressão strategos, que significava "a arte do general de exército" (Evered apud Mintzberg; Quinn, 2001). O sentido da estratégia, que antigamente representava uma forma de vencer o inimigo, foi ampliado com o passar do tempo para outros campos do relacionamento humano, político, econômico e também para o contexto empresarial. No contexto empresarial, seu significado foi preservado no sentido de aumento das chances de vitória. A evolução do conceito de estratégia no contexto organizacional resultou na definição do termo como a noção das metas e dos objetivos básicos de longo prazo de uma organização, bem como a adoção de cursos de ação e a alocação de recursos para realizar essas metas.

No campo organizacional não é possível adotar-se um único conceito para estratégia, de acordo com os autores, que possa ser utilizado uniformemente em todas as empresas. 0 conceito de estratégia pode depender da organização que a adota e da sua visualização da forma de atuação empresarial. Assim, a estratégia para algumas empresas possui uma relação com os planos e para outras está mais relacionada à forma de concorrer no mercado ou ao padrão de agir. Mintzberg, Ahlstrand e Lampel (2000) definem dez escolas para o pensamento acerca da estratégia, distribuindo-as em três grupos, quanto à natureza do processo: prescritivas, descritivas e de configuração.

O grupo prescritivo se preocupa em prescrever como deve ser a formulação da estratégia. O segundo grupo, descritivo, se preocupa mais com aspectos específicos do processo e com a descrição de como se formulou a estratégia e menos em pesquisar como, especificamente, a estratégia deveria ser formulada. O terceiro grupo, que possui apenas uma escola, busca uma concepção mais ampla que define, agrupa e combina elementos de todas as outras escolas na busca de uma definição mais ampla da formulação estratégica. 
Analisando-se a perspectiva formal da estratégia como um plano, sugere-se a elaboração de um planejamento a partir de decisões estruturadas em um processo. Assim, o Planejamento Estratégico de Negócio (PEN) pode ser considerado como um sistema integrado de decisões, capaz de produzir dados e informações para ajudar os gestores a pensar estrategicamente, apoiando a articulação das estratégias ou visões de futuro (MINTZBERG; QUINN, 2001).

A relação do PEN com a estratégia é que ele representa um plano formal para disseminar a consciência de elementos estratégicos de uma organização: pontos fortes,pontos fracos, objetivos, metas, ameaças e oportunidades, dentre outros elementos. É considerado uma programação estratégica que forma uma articulação e a elaboração de visões que os gestores obtêm de diversas fontes, tanto de vivências e experiências pessoais, quanto de números coletados em planilhas, relatórios, bancos de dados, agregações ou sínteses. Essas informações são utilizadas para definir a direção que o negócio deve seguir.

Da mesma forma que o PEN é formulado para o negócio, o Planejamento Estratégico de TI (PETI) relaciona-se com a estratégia de Tecnologia da Informação. Consiste em um conjunto de ferramentas e técnicas utilizadas para a identificação de elementos na área de TI que possibilitam apoiar os negócios empresariais e o Alinhamento estratégico de tecnologia da informação: análise de modelos e propostas para pesquisas futuras, desenvolvimento de arquiteturas de informação, objetivos, estratégias e aplicações estratégicas. As ferramentas e técnicas utilizadas devem basear-se nas necessidades dos usuários da TI, sendo o resultado do processo um plano formal, semelhante ao PEN, para a área de TI.

Outro conceito relacionado ao planejamento da área de TI foi identificado por Lederer e Sethi (1992), os quais definem o Planejamento Estratégico de Sistemas de Informação, da sigla SISP (Strategic Information Systems Planning), considerado o processo utilizado para identificar o conjunto de aplicações baseadas em sistemas de informação que apoiarão a organização na execução de seus planejamentos de negócios e na realização de seus objetivos. O SISP também auxilia na identificação das bases de dados, aplicativos e possibilidades que melhor atenderão às necessidades identificadas.

Fazendo a relação da tecnologia com o processo de planejamento e a estratégia, Abetti (2001) ressalta três posicionamentos da tecnologia dentro do processo de planejamento: como um elemento reativo, como um elemento que leva a empresa a ser proativa e como um direcionador da estratégia empresarial. Da mesma forma, pode-se analisar o Alinhamento Estratégico entre $\mathrm{TI}$ e os negócios, pois a TI pode ser utilizada de uma forma que possa automatizar processos de uma forma que busque o apoio e as decisões para a proatividade (como em sistemas de informações gerenciais e em sistemas de inteligência empresarial) ou como um elemento que faz parte dos processos de negócios da organização, alterando e sendo alterado pelo negócio e pelo ambiente, em um modelo sistêmico.

De acordo com Luftman e Brier (1999), o alinhamento estratégico é um conceito chave para os executivos de negócios: refere-se à aplicação da TI do modo correto, no tempo correto e em harmonia com as estratégias de negócios. O alinhamento pode tanto mostrar como a TI se alinha ao negócio, quanto mostrar como o negócio pode se alinhar com a TI. Os autores relatam que de forma frustrante as organizações parecem achar difícil ou impossível utilizar o poder da $\mathrm{TI}$ para benefícios em longo prazo, mesmo sendo evidente seu poder de transformar indústrias e mercados.

O alinhamento estratégico da área de TI vem sendo estudado há anos como um objetivo a ser buscado pelas áreas de TI das organizações. Um dos pressupostos básicos é o alinhamento 
entre o Planejamento Estratégico do Negócio (PEN) e o Planejamento Estratégico de TI (PETI). Diversos conceitos de alinhamento estratégico podem ser ressaltados, todos eles enfatizando a importância de atingi-lo.

Quando falamos de alinhamento de TI e estratégias corporativas, é importante fixar conceitos básicos que permitirão uma melhor compreensão dos elementos e funções de um e de outro. A tabela 1 a seguir apresenta uma síntese dos principais conceitos acerca do alinhamento estratégico, o objeto de estudo, a importância para a organização, bem como a referência a esses pesquisadores do alinhamento estratégico nos últimos anos.

Tabela 1: Síntese dos conceitos do Alinhamento Estratégico de TI

\begin{tabular}{l|l|l}
\hline Autor & Ano & Conceito \\
\hline $\begin{array}{l}\text { Chan apud } \\
\text { Brodbeck et al }\end{array}$ & 2003 & $\begin{array}{l}\text { O alinhamento entre Plano Estratégico do Negócio (PEN) e o Plano } \\
\text { Estratégico da TI (PETI) é a adequação entre a orientação estratégica do } \\
\text { negócio e a orientação estratégica de TI. }\end{array}$ \\
\hline Reich e Benbasat & 1996 & $\begin{array}{l}\text { A ligação entre Plano Estratégico do Negócio (PEN) e o Plano Estratégico } \\
\text { da TI (PETI) corresponde ao grau no qual a missão, os objetivos e os } \\
\text { planos de TI refletem, suportam, e são suportados pela missão, pelos } \\
\text { objetivos e pelos planos de negócio. }\end{array}$ \\
\hline $\begin{array}{l}\text { Henderson e } \\
\text { Venkatraman }\end{array}$ & 1993 & $\begin{array}{l}\text { O alinhamento estratégico corresponde à adequação e integração } \\
\text { funcional entre ambiente externo (mercados) e interno (estrutura } \\
\text { administrativa e recursos financeiros, tecnológicos e humanos) para } \\
\text { desenvolver as competências e maximizar o desempenho organizacional }\end{array}$ \\
\hline King & 1988 & $\begin{array}{l}\text { O alinhamento entre Plano Estratégico do Negócio (PEN) e o Plano } \\
\text { Estratégico da TI (PETI) é alcançado quando o conjunto de estratégias de } \\
\text { sistemas (objetivos, obrigações e estratégias) é derivado do conjunto } \\
\text { estratégico organizacional (missão, objetivos e estratégias) }\end{array}$ \\
\hline
\end{tabular}
Fonte: Elaborada pelo autor

As particularidades dos estudos científicos de cada autor obviamente trazem contribuições singulares, mas em todos esses conceitos, percebe-se claramente que os autores retratam que a gestão da Tl está totalmente guiada pelos objetivos estratégicos organizacionais.

$\mathrm{Na}$ última década, o alinhamento estratégico entre a TI e negócio tem sido um tema constantemente discutido tanto no meio acadêmico quanto no meio corporativo.

No meio acadêmico nacional, muitos estudos têm sido realizados para examinar os benefícios do alinhamento entre $\mathrm{TI}$ e negócio. Temos como referência vários artigos publicados nos encontros do ENANPAD, 3Es, e revistas especializadas.

No meio corporativo, os executivos de TI consideram esse alinhamento como um dos objetivos principais da sua área, tendo em vista a possibilidade de identificação de novas oportunidades e obtenção de vantagens competitivas baseadas em soluções de TI (BRODBECK; HOPPEN, 2003).

Uma survey periódica realizada pela SIM (Society for Information Management) demonstra que o tema Alinhamento entre TI e Negócios foi o segundo do ranking na última edição da pesquisa (2012), e o primeiro na edição de 2011. A pesquisa trata dos temas mais relevantes para a gestão da $\mathrm{TI}$, e mostra que o alinhamento estratégico é parte dos temas top ten dos últimos anos, tendo uma oscilação entre o primeiro e terceiro lugares.

Apesar da concordância geral sobre o impacto positivo do alinhamento nas organizações, na prática ainda existem alguns problemas no processo como um todo: comunicação entre os departamentos, perda de recursos ou de comprometimento e solicitações que não estão alinhadas ao planejamento estratégico. 
Além desse cenário, existe também a necessidade de maior transparência das organizações à sociedade e aos seus acionistas. Mesmo sendo considerado um tema recente na área de pesquisa, a governança corporativa passou a ser uma temática recorrente nas organizações (IBGC, 2010). Episódios como os das fraudes contábeis nas empresas norte-americanas Enron e World Com Gill (2002) intensificaram os mecanismos para resguardar acionistas, clientes, fornecedores, governo e a sociedade como um todo de eventuais dolos decorrentes da má gestão nas empresas norte-americanas através da adoção de melhores práticas da governança corporativa.

\subsection{MODELO DE ALINHAMENTO ESTRATÉGICO}

O modelo utilizado como base nesta pesquisa para fundamentar a avaliação do alinhamento estratégico da TI na empresa estudada procura incluir e equacionar todos estes aspectos ou desafios, conforme pode ser observado na Figura 1.

Os autores entendem o ajuste estratégico como a clássica relação entre as fases da elaboração e implementação da estratégia corporativa. Evidente que a estratégia geral da organização deve ser desdobrada nas diferentes unidades de negócio, alterando estrategicamente as estruturas administrativas, processos de negócio e influenciando mudanças comportamentais. Entretanto, este processo de desdobramento ou implementação precisa constantemente estar fornecendo um feedback, que permita a rápida detecção de necessidades de ajustes na estratégia corporativa. Talvez em função das cada vez mais frequentes alterações no panorama competitivo e concorrencial (decorrente de inovações tecnológicas, globalização, formação de blocos econômicos, etc.) esta necessidade de ajustes estratégicos tem se tornado cada vez mais importante.

Nesta pesquisa, optou-se por denominar este panorama competitivo no qual as empresas estão inseridas como "ambiente externo"; ao conjunto de infra-estrutura administrativa, processos de negócio e pessoas, optou-se por denominar "ambiente interno".

Quanto à "integração estratégica", Henderson e Vankatraman (1993) colocam que os projetos de TI devem estar diretamente relacionados aos objetivos estratégicos, de forma que possam implementar os sistemas e soluções que viabilizem o alcance desses objetivos. Essa integração não é imediata e/ou tranquila, tendo em vista as inúmeras mudanças organizacionais decorrentes de projetos de tecnologia da informação, as quais envolvem questões de poder, política, cultura, e várias outras. 


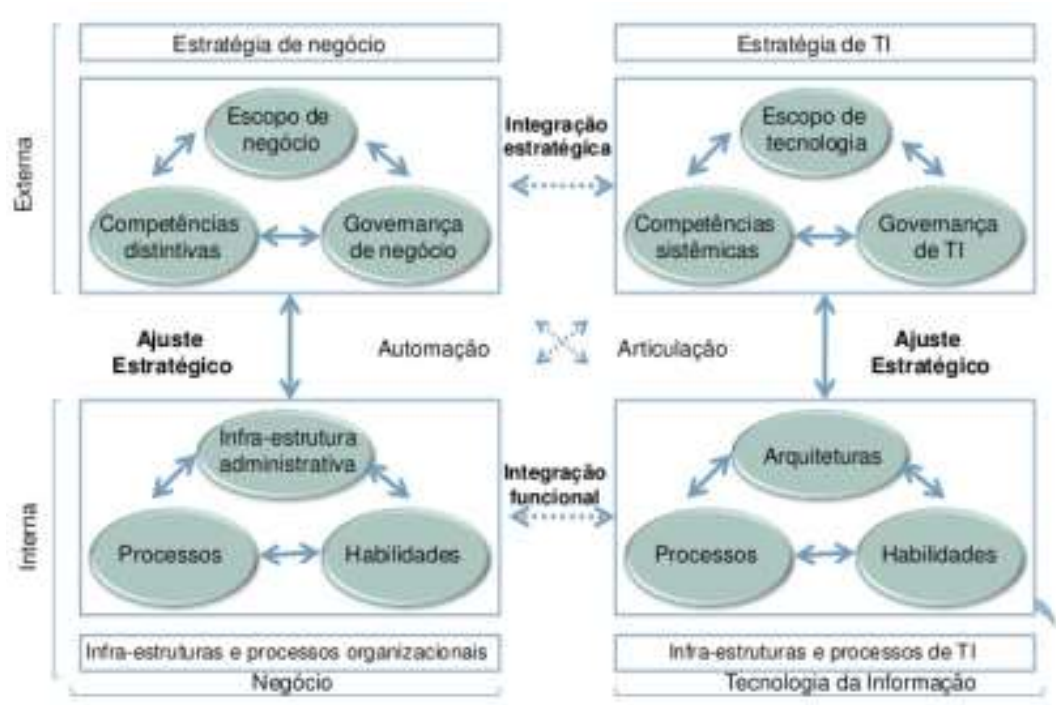

Figura 1: Modelo de Henderson e Venkatraman

Fonte: Henderson (1993)

A "integração funcional" trata da ligação entre a infraestrutura e processos organizacionais; e infraestrutura e processos de TI. Mesmo que a implementação de projetos estratégicos seja considerada prioridade, a relação da $\mathrm{Tl}$ com as outras pessoas, processos e infraestrutura de suporte para as operações rotineiras do negócio não pode pôr em perigo todo o conjunto da empresa.

Portanto, o alinhamento entre planejamento e as estratégias do negócio e da TI constitui-se em relacionar verticalmente (de cima para baixo e vice-versa) tanto o ambiente externo quanto o interno, provendo uma adequação estratégica e da estrutura interna para atender ao posicionamento de mercado da organização; e horizontalmente os planejamentos das dimensões negócios e TI através da integração dos diferentes relacionamentos funcionais da organização pessoas, processos, e infraestrutura (HENDERSON; VENKATRAMAN, 1993).

\subsection{BALANCED SCORECARD (BSC)}

Ao longo do tempo, as organizações têm buscado e adotado práticas e ferramentas gerenciais com o objetivo de potencializar suas operações, melhorar seus resultados e se posicionar competitivamente no mercado.

No início da década de 90, Johnson e Kaplan realizaram estudo para identificar quais seriam as práticas adotadas pelas empresas americanas, de forma a controlar seu desempenho. Nessa pesquisa, identificou-se que todos os métodos utilizados haviam surgido nos últimos 100 anos e tinham vindo da contabilidade gerencial.

Em Harvard, os Professores Robert S. Kaplan e David P. Norton propuseram uma nova abordagem para resolver problemas de mensuração frente aos novos desafios organizacionais das empresas inseridas na economia do conhecimento.

Os autores constataram que os indicadores financeiros isoladamente se mostravam incapazes de medir as atividades criadoras de valor relacionadas com os ativos intangíveis, como habilidades, competências e motivação dos empregados, bancos de dados e tecnologias da informação, processos, inovação em produtos e serviços, relacionamentos com os clientes, imagem da organização e outras (SILVA, 2009)

Em 1992, Kaplan e Norton apresentaram um artigo na Harvard Business Review, sob o título "The Balanced Scorecard measures that drive performance". Um sistema para medir o desempenho das operações atuais da organização e os indicadores futuros de desempenho, por 
meio de quatro perspectivas de negócio: Financeiro, Cliente, Processos Internos e Aprendizado e Crescimento.

O BSC é um sistema de informação para gerenciamento da estratégia empresarial, traduz a missão e a estratégia da organização em um conjunto abrangente de medidas de desempenho financeiras e não-financeiras, que serve de base para um sistema de medição e gestão estratégica.

É importante ressaltar que o BSC não deve apenas derivar da estratégia organizacional, mas tem que deixar transparecer essa estratégia aos observadores possibilitando, também, a visualização dos seus objetivos e medidas. Quando atinge esse grau de transparência, o BSC consegue traduzir a visão e a estratégia num conjunto integrado de medidas de desempenho (KAPLAN; NORTON, 1997)

A partir da implementação do BSC, as organizações caminham de um Sistema de Controle Gerencial, projetado em torno de um referencial financeiro de curto prazo e orientado para o controle, para um Sistema Gerencial Estratégico, projetado em torno da visão estratégica de longo prazo.

De acordo com o autor Renato Silva (2009), os objetivos mais significantes do BSC são: esclarecer e traduzir a visão e a estratégia; comunicar e associar objetivos e medidas estratégicas; planejar, estabelecer metas e alinhar iniciativas, e melhorar o feedback e o aprendizado estratégico.

O BSC é um modelo de gestão que auxilia as organizações a traduzir a estratégia em objetivos, fazendo com que ela seja comunicada de forma clara, que alinha os ativos da organização com foco na visão, que cria um sentido para a mobilização do capital humano e que permite a implementação de uma cultura de aprendizado com constantes ciclos de atualização da estratégia.

Dessa forma, o BSC preenche uma grande lacuna deixada pela maioria dos sistemas gerenciais, que é a falta de um processo sistemático para implementar e obter feedback sobre a estratégia utilizada. Os processos gerenciais construídos a partir do BSC asseguram que a empresa fique alinhada e focalizada na implementação da estratégia.

O processo de elaboração de um BSC deve ser realizado de acordo com as características de cada organização, uma vez que toda e qualquer organização possui características e particularidades. Portanto, o BSC não pode vir como um pacote pronto e sim deve ser avaliada sua aplicação em cada caso, adaptado ao formato e necessidade da organização.

O resultado essencial desta ferramenta é a sua capacidade de tornar possível aos administradores o poder da avaliação, traduzindo a visão e a estratégia de uma unidade de negócios em objetivos e medidas tangíveis.

Assim, o BSC supre vários questionamentos e necessidades de uma organização, possibilitando identificar novos rumos e oportunidades para o alinhamento da estratégia e o desenvolvimento organizacional.

\section{METODOLOGIA DA PESQUISA}

Neste estudo foi realizada uma pesquisa do tipo exploratória descritiva, fazendo uma abordagem qualitativa acerca do problema.

Em um estudo exploratório, o pesquisador parte de uma hipótese e aprofunda seu estudo nos limites de uma realidade específica, buscando antecedentes, maiores conhecimentos, para, em seguida, planejar uma pesquisa descritiva (YIN, 2001). Um estudo exploratório é apropriado 
quando o conhecimento disponível é insuficiente para estabelecer as relações de causa e efeito. Os estudos exploratórios não elaboram hipóteses a serem testadas, restringindo-se a buscar mais informações sobre o tema estudado, de acordo com os objetivos estabelecidos (CERVO; BERVIAN, 2003).

O estudo descritivo pretende descrever 'com exatidão' os fatos e fenômenos de determinada realidade. Outros estudos descritivos denominam-se estudos de casos. Esses estudos têm por objetivo aprofundar a descrição de determinada realidade (TRIVIÑOS, 1987, p. 58).

O método escolhido, é o estudo de caso, caracteriza-se pelo "estudo profundo e exaustivo de um ou poucos objetos, de maneira que permita o seu amplo conhecimento, tarefa praticamente impossível mediante outros delineamentos considerados" (GIL, 2002). De acordo com Yin (2001), o estudo de caso é uma pesquisa empírica que investiga um fenômeno contemporâneo, dentro de um contexto de vida real, especialmente quando os limites entre o fenômeno e o contexto não estão claramente definidos.

Para a coleta de dados, foram utilizadas as técnicas de análise documental, observação direta e entrevista focalizada. A técnica da análise documental, como o nome sugere, refere-se ao estudo de documentos da empresa. Documento é toda e qualquer fonte ou base de conhecimentos acessível para consulta (PÁDUA, 1997). As fontes foram selecionadas de forma a garantir a pertinência aos objetivos da pesquisa. A observação direta consiste no contato pessoal e estreito do pesquisador com o objeto do estudo, permitindo-Ihe utilizar seus conhecimentos e experiências como auxiliares no processo de compreensão e interpretação desse objeto.

As informações coletadas para este trabalho foram obtidas através de entrevistas com o Gerente de Projetos da empresa, Gestores das áreas de $\mathrm{TI}$ e alguns Gestores das áreas administrativas da empresa. Os documentos estudados fazem parte da metodologia do Escritório de Gerenciamento de Projetos (EGP) da organização.

O critério utilizado para a escolha da organização foi por conveniência, ou seja, foi estudada uma organização que apresentou motivação e condição para a realização do trabalho.

A organização objeto deste estudo é uma Universidade privada do Nordeste, com mais de 30 anos de atividades. Oferece cursos de Graduação, Pós-Graduação, Educação a Distância e Cursos Técnicos, com polos em diversas cidades do país.

$\mathrm{Na}$ área de $\mathrm{Tl}$, a organização conta com um Gerente de $\mathrm{Tl}$, Escritório de Projetos, Operações e Redes, Desenvolvimento de Sistemas, Manutenção Técnica e Controles Internos de TI.

\section{RESULTADOS E DISCUSSÕES}

\subsection{PROCESSO DE ALINHAMENTO DOS PROJETOS}

Anualmente entre os meses de outubro e novembro, é realizado pelo Escritório de Gerenciamento de Projetos (EGP) um levantamento com as principais áreas organizacionais da IES: Acadêmica, Financeira, Marketing, Biblioteca, Atendimento, Contabilidade, Recursos Humanos e Diretoria Administrativa. Esse levantamento procura identificar necessidades de $\mathrm{TI}$ dessas áreas para planejar possíveis projetos para o ano seguinte.

Inicialmente o EGP marca uma primeira reunião para entrevistar o Gestor da área, onde é realizada uma conversa sobre o que o setor precisa na área de sistemas, infraestrutura de $\mathrm{Tl}$, etc.

A partir de pontos conversados, são discutidas possíveis soluções. Essas soluções podem se tornar um projeto de aquisição e implantação de um software de terceiro, aquisição de serviço 
externo, projeto de desenvolvimento interno de sistema, recurso de infraestrutura de rede, recurso de datacenter, etc.

Normalmente, uma ou duas reuniões são suficientes para se definir qual a solução ideal para atender aquela necessidade da área. Dependendo da solução proposta, pode ser identificada a necessidade de alinhamento com outra(s) área(s), a fim de definir algum processo entre elas antes de se chegar a alguma conclusão.

Definida a solução, o Gestor da área é então orientado a efetuar uma Solicitação de Projeto, através de um formulário apropriado. A solicitação oficializa o pedido do Gestor junto ao EGP.

Esse formulário contém perguntas que ajudam o EGP a dimensionar o projeto solicitado. São requisitadas informações sobre o retorno financeiro do projeto para instituição, seja por diminuição de custos ou aumento de receita. Há também informações voltadas às 4 perspectivas do BSC, onde o gestor informa quais perspectivas o projeto irá atender (KAPLAN; NORTON, 1997).

Alguns projetos não trazem retorno financeiro algum, e sim gastos para a instituição, mas são necessários para atender alguma mudança de regra ou para atender alguma mudança da legislação: Ministério da Educação, Receita Federal, Ministério do Trabalho ou outro órgão governamental.

\subsection{ANÁLISE E CLASSIFICAÇÃO DOS PROJETOS}

Recebidos os formulários de Solicitação de Projetos, o EGP inicia então o trabalho de análise das solicitações. Os projetos são colocados em uma planilha, a fim de se obter uma visão geral e sintetização das informações do formulário de Solicitação de Projeto.

Por questões de ética e sigilo das informações coletadas, os dados apresentados na tabela 2 a seguir foram manipulados.

Tabela 2. Lista de Projetos

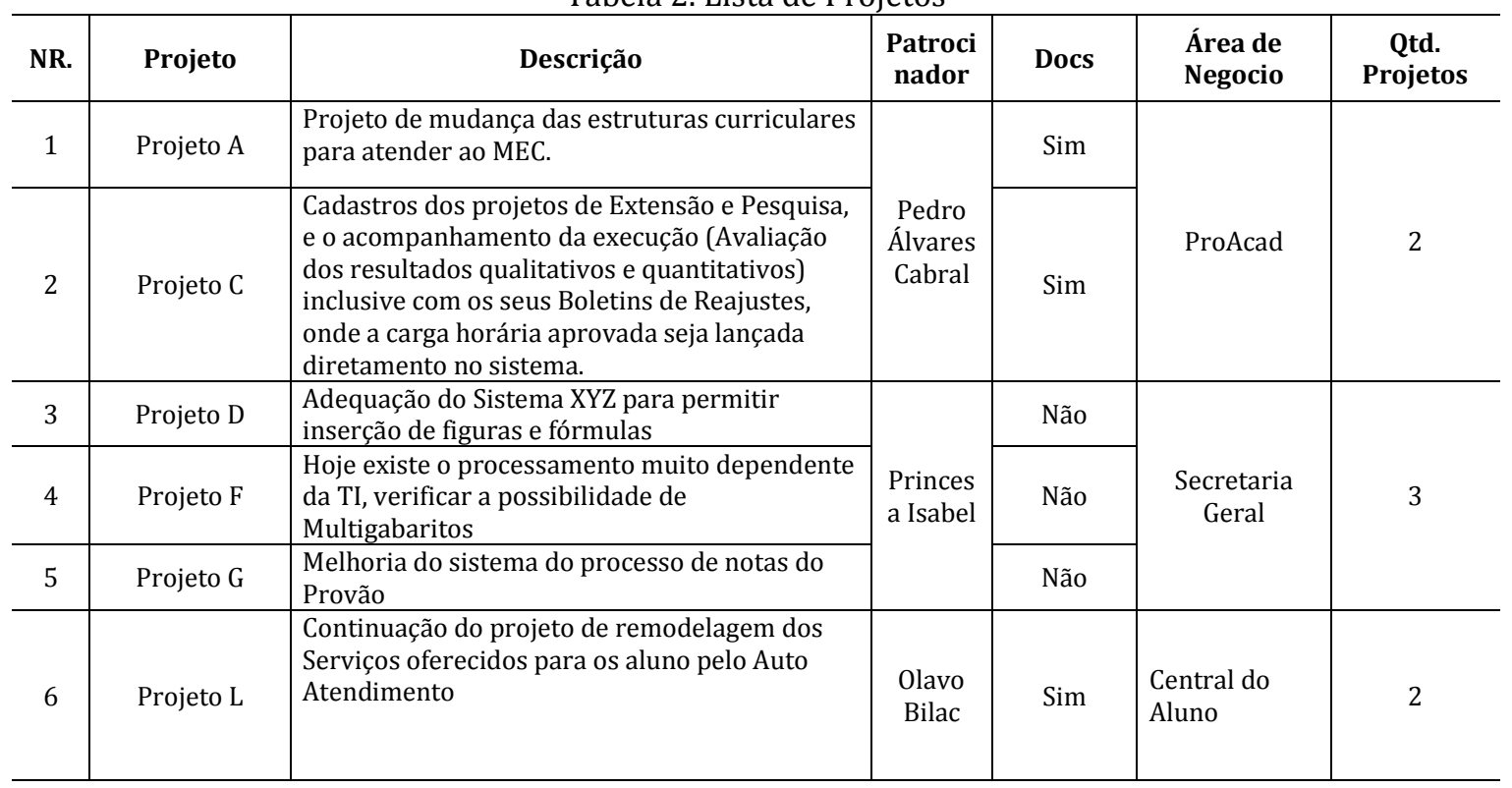




\begin{tabular}{l|l|l|l|l|l}
\hline 7 & Projeto P & Adequação dos relatórios do marketing & & Sim & $\begin{array}{l}\text { Controle de } \\
\text { Vendas }\end{array}$ \\
\hline 8 & Projeto X & $\begin{array}{l}\text { Implantação de Módulos faltantes do Sistema } \\
\text { de ERP }\end{array}$ & $\begin{array}{l}\text { D. João } \\
\text { VI }\end{array}$ & Sim & Financeiro \\
\hline
\end{tabular}

Fonte: Elaborada pelo autor

Os projetos que dizem respeito a infraestrutura de $\mathrm{TI}$ e os projetos de âmbito institucional (multi-setoriais) são tratados de forma diferenciada do que será exposto a seguir. Estes projetos podem envolver investimentos de CAPEX (expressão inglesa de Capital Expenditure) e são analisados pelo Gerente de TI e Gerente de Operações de $\mathrm{Tl}$, a fim de identificar se poderão ser atendidos no ano seguinte em virtude do envolvimento de recursos financeiros.

Os projetos referentes a Sistemas (aquisição e desenvolvimento) são separados então em uma segunda planilha, onde será estudada sua complexidade, conforme demonstra a tabela 3.

Tabela 3. Planilha de Análise de Complexidade

\begin{tabular}{|c|c|c|c|c|c|c|c|c|}
\hline \multirow{3}{*}{ Projeto } & \multicolumn{8}{|c|}{ Complexidade } \\
\hline & \multirow{2}{*}{$\begin{array}{c}\text { Tecnologia } \\
\text { Tipo }\end{array}$} & \multicolumn{2}{|l|}{ Tempo } & \multicolumn{2}{|c|}{$\begin{array}{c}\text { Alto Impacto/ } \\
\text { Impacto } \\
\text { Financeiro }\end{array}$} & \multicolumn{2}{|c|}{$\begin{array}{c}\text { Tem } \\
\text { Integração }\end{array}$} & \multirow[t]{2}{*}{ Total } \\
\hline & & Tipo & Pontos & Tipo & Pontos & Tipo & Pontos & \\
\hline Projeto A & Delphi & $>48 \mathrm{~h} \mathrm{e}<8$ semanas & 1 & Não & 1 & Não & 1 & 6 \\
\hline Projeto $\mathrm{C}$ & JAVA & $>3$ meses $\mathrm{e}<6$ meses & 3 & $\operatorname{Sim}$ & 2 & Sim & 2 & 12 \\
\hline Projeto D & Delphi & $>48 \mathrm{~h} \mathrm{e}<8$ semanas & 1 & Não & 1 & Não & 1 & 6 \\
\hline Projeto F & Delphi & $>48 \mathrm{~h} \mathrm{e}<8$ semanas & 1 & Sim & 2 & Sim & 2 & 8 \\
\hline Projeto G & ASP/PHP & $>8$ semanas $\mathrm{e}<3$ meses & 2 & Sim & 2 & Sim & 2 & 10 \\
\hline Projeto L & JAVA & $>8$ semanas $\mathrm{e}<3$ meses & 2 & Não & 1 & Não & 1 & 9 \\
\hline Projeto $\mathrm{P}$ & ASP/PHP & $>3$ meses e $<6$ meses & 3 & Sim & 2 & Sim & 2 & 11 \\
\hline Projeto $\mathrm{X}$ & ASP/PHP & $>8$ semanas $\mathrm{e}<3$ meses & 2 & Não & 1 & Não & 1 & 8 \\
\hline
\end{tabular}

Fonte: Elaborada pelo autor

Para determinar o nível de complexidade de um projeto, foram definidos pelo EGP e pela Equipe de Desenvolvimento de Sistemas alguns critérios de complexidade: tipo da tecnologia envolvida, o tempo estimado projeto (range), se há impacto financeiro no projeto e se existe integração entre sistemas. Esses critérios ajudam a determinar se o projeto é muito ou pouco complexo, e podem ser melhor visualizados melhor na tabela 4 a seguir.

Tabela 4. Critérios de Complexidade

\begin{tabular}{|c|c|c|c|c|c|c|c|c|c|}
\hline \multicolumn{10}{|c|}{ Critérios de Complexidade } \\
\hline \multicolumn{2}{|c|}{ Tecnologia } & \multicolumn{4}{|c|}{ Tempo } & \multicolumn{2}{|c|}{ Alto Impacto financeiro } & \multicolumn{2}{|c|}{ Integração } \\
\hline Classificação & Pontos & Classificação & Pontos & $\begin{array}{l}\text { Qtd. } \\
\text { Horas }\end{array}$ & $\begin{array}{l}\text { Qtd } \\
\text { Meses }\end{array}$ & Classificação & Pontos & Classificação & Pontos \\
\hline Delphi & 3 & $>48 \mathrm{~h} \mathrm{e}<8$ semanas & 1 & 440 & 2 & Não & 1 & Não & 1 \\
\hline ASP/PHP & 4 & $>8$ semanas e $<3$ meses & 2 & 660 & 3 & Sim & 2 & Sim & 2 \\
\hline JAVA & 5 & $>3$ meses e $<6$ meses & 3 & 1320 & 6 & & & & \\
\hline Outros & 5 & $>6$ meses & 4 & 2640 & 12 & & & & \\
\hline
\end{tabular}

Fonte: Elaborada pelo autor 
Além da complexidade, é necessário calcular também qual o custo operacional do projeto. Este custo é calculado baseado em horas de trabalho das equipes envolvidas.

Abaixo seguem a tabela 5 que representam os valores das equipes de Desenvolvimento e ERP para efeito de cálculo do custo/orçamento do projeto. Os valores foram alterados e se tratam de dados fictícios.

Tabela 5. Valor de hora de trabalho por equipe - Equipe Desenvolvimento

\begin{tabular}{|c|c|c|c|}
\hline \multicolumn{4}{|c|}{ Equipe Desenvolvimento } \\
\hline Qtd. & Função & $\mathrm{R} \$ \mathbf{H} /$ Hora & \% Tempo \\
\hline 1 & Analista de Requisitos & 1,00 & 20 \\
\hline 1 & WEB Designer & 1,00 & 10 \\
\hline 1 & Analista de Sistemas & 1,80 & 30 \\
\hline 1 & Desenvolvedor & 0,90 & 30 \\
\hline 1 & Analista de Teste & 1,50 & 10 \\
\hline & & & 100 \\
\hline \multicolumn{4}{|c|}{ Equipe ERP } \\
\hline Qtd. & Cargo & $\mathbf{R} \$$ Hora & \%Tempo \\
\hline 1 & Analista ERP & 1,80 & 90 \\
\hline \multirow[t]{2}{*}{1} & Analista de Teste & 1,50 & 10 \\
\hline & & & 100 \\
\hline
\end{tabular}

Fonte: Elaborada pelo autor

As partir desses valores, o custo estimado do projeto é calculado na planilha demonstrada na tabela 6 . Os dados apresentados são fictícios, apenas para ilustrar a forma de funcionamento da planilha.

Tabela 6. Planilha de Cálculo de Retorno Financeiro e Custo do Projeto

\begin{tabular}{|c|c|c|c|c|c|c|c|c|}
\hline \multirow{3}{*}{ Projeto } & \multicolumn{5}{|c|}{ Retorno } & \multirow{2}{*}{\multicolumn{3}{|c|}{ Orçamento/ Custo }} \\
\hline & \multirow{2}{*}{\multicolumn{2}{|c|}{$\begin{array}{c}\begin{array}{c}\text { Diminuição de } \\
\text { Custo (Ano) }\end{array} \\
\text { R\$ }\end{array}$}} & \multirow{2}{*}{\multicolumn{2}{|c|}{$\begin{array}{c}\text { Aumento de Receita (Ano) } \\
\text { R\$ }\end{array}$}} & \multirow{2}{*}{$\begin{array}{c}\text { Total } \\
\mathbf{R} \$\end{array}$} & & & \\
\hline & & & & & & Qtd. Horas & $\mathrm{RS}$ & RȘ/ Mês \\
\hline Projeto $\mathrm{A}$ & $\mathrm{R} \$$ & $1.000,00$ & $\mathrm{R} \$$ & $11.600,00$ & $\mathrm{R} \$ 12.600,00$ & 440,00 & $\mathrm{R} \$ \mathbf{5 . 0 6 0 , 0 0}$ & $\mathrm{R} \$ 2.530,00$ \\
\hline Projeto C & $\mathrm{R} \$$ & $12.356,00$ & $\mathrm{R} \$$ & $14.000,00$ & $R \$ 26.356,00$ & $1.320,00$ & $R \$ 15.180,00$ & $\mathrm{R} \$ 2.530,00$ \\
\hline Projeto D & $\mathrm{R} \$$ & 500,00 & $\mathrm{RS}$ & $71.100,00$ & $R \$ 71.600,00$ & $1.320,00$ & $\mathrm{R} \$ 15.180,00$ & $\mathrm{R} \$ \mathbf{2 . 5 3 0 , 0 0}$ \\
\hline Projeto F & $\mathrm{RS}$ & $16.122,00$ & 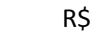 & - & $R \$ 16.122,00$ & 440,00 & $R \$ 5.060,00$ & $\mathrm{R} \$ 2.530,00$ \\
\hline Projeto G & $\mathrm{R} \$$ & $2.000,00$ & $\mathrm{RS}$ & $36.000,00$ & $\mathrm{R} \$ \mathbf{3 8 . 0 0 0 , 0 0}$ & 660,00 & $\mathrm{RS} \quad 7.590,00$ & $\mathrm{R} \$ \mathbf{2 . 5 3 0 , 0 0}$ \\
\hline Projeto L & $\mathrm{RS}$ & $6.500,00$ & $\mathrm{RS}$ & $38.600,00$ & $\mathrm{R} \$ 45.100,00$ & 660,00 & $\mathrm{R} \$ \mathbf{7 . 5 9 0 , 0 0}$ & $\mathrm{R} \$ 2.530,00$ \\
\hline Projeto $\mathrm{P}$ & $\mathrm{RS}$ & - & $\mathrm{RS}$ & - & R\$ $\quad-$ & 660,00 & $\mathrm{R} \$ 7.590,00$ & $\mathrm{R} \$ \mathbf{2 . 5 3 0 , 0 0}$ \\
\hline Projeto $\mathrm{X}$ & $\mathrm{R} \$$ & - & $\mathrm{R} \$$ & - & $\mathbf{R} \$$ & 660,00 & $R \$ 7.590,00$ & $\mathrm{R} \$ 2.530,00$ \\
\hline
\end{tabular}

Fonte: Elaborada pelo autor

O retorno financeiro do projeto, seja ele por diminuição de custos ou aumento de receita, é calculado e informado pelo Gestor da área no formulário de Solicitação de Projeto.

O orçamento/custo do projeto é calculado baseado na quantidade de horas prevista do projeto versus o valor proporcional da hora dos colaboradores envolvidos. Baseado no custo total do projeto, é calculado também o seu valor mensal para comparativo. 
A partir das planilhas de Análise de Complexidade e de Retorno Financeiro e Custo do Projeto, é produzido então um Gráfico de Dispersão, onde todos os projetos listados são classificados dentro de quatro quadrantes definidos por complexidade e retorno financeiro, conforme demonstrada na figura 2:

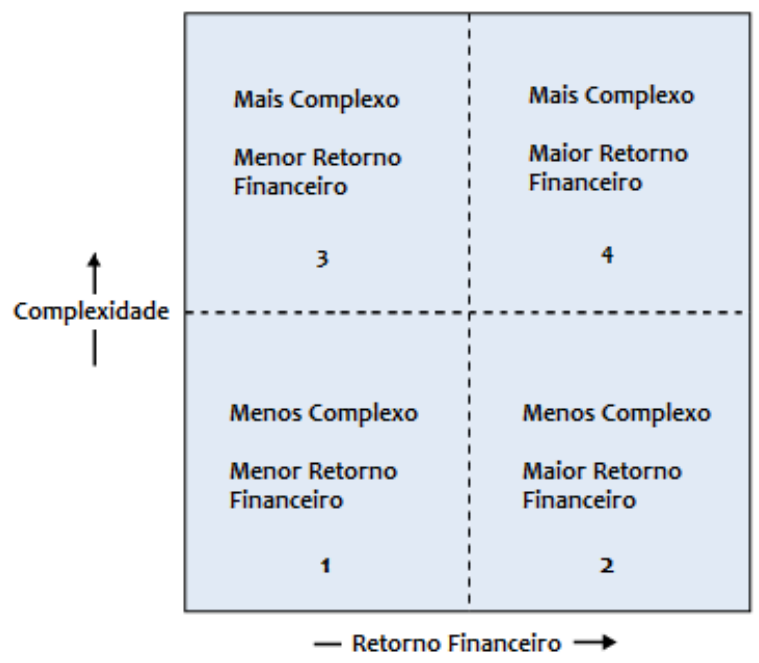

Figura 2. Quadrantes do Gráfico de Dispersão

O quadrante no qual um projeto é classificado nos ajuda a entender seu nível de complexidade e retorno financeiro para a organização.

Baseados na montagem do Gráfico de Dispersão, o EGP, junto com outras áreas de $\mathrm{TI}$ envolvidas, analisam e criam um roadmap dos projetos que supostamente serão aprovados pelo Comitê Executivo. Este roadmap ajuda a determinar qual a capacidade do Setor de TI em realizar os projetos, visto que dificilmente será possível a realização de todos os projetos durante o ano.

O trabalho do EGP é então finalizado até que aconteça a análise do gráfico montado pelo Comitê Executivo da organização em reunião realizada para alinhamento dos projetos de $\mathrm{TI}$ versus objetivos estratégicos, para o ano seguinte.

Alinhamento com o Comitê Executivo

O Comitê Executivo da IES é um grupo de gestores responsável por estudar, pensar, discutir, debater, definir, estabelecer, outorgar e direcionar ações estratégicas organizacionais para que a instituição atinja seus objetivos. É formado pelos Gestores das principais áreas da instituição: Reitoria, Diretoria Administrativa, Jurídica, Acadêmica, Financeira, Marketing, Recursos Humanos e Tecnologia da Informação. O grupo se reúne semanalmente e discute os temas em evidência para o direcionamento estratégico.

Anualmente, após o levantamento dos projetos pelo EGP, é marcada então uma reunião para discussão e aprovação dos projetos de TI. Este processo está relacionado à "integração estratégica", de Henderson e Vankatraman (1993).

Dispondo os projetos das planilhas anteriores no gráfico de dispersão, temos então a seguinte configuração apresentada na figura 3: 


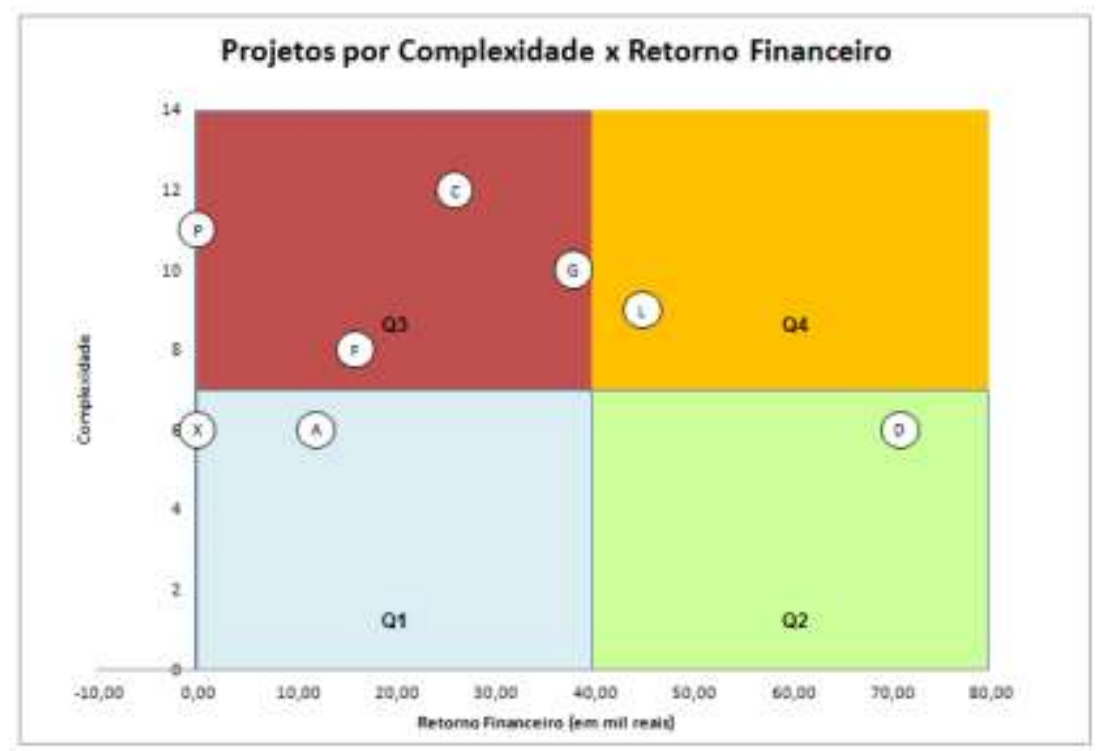

Figura 3. Projetos por Complexidade x Retorno Financeiro

No gráfico de dispersão, os projetos são indicados por "bolinhas" dispostas em eixo cartesiano e quadrantes, indicando os projetos com maior e menor complexidade e maior e menor retorno financeiro.

Baseado nessas informações, o Comitê Executivo discute os projetos de maior relevância para a organização. Os projetos dispostos no quadrante Q2 (verde) são os possíveis aprovados, levando em consideração que são os mais rentáveis e de menor complexidade. Em seguida, são analisados os projetos na região do quadrante Q4 (amarela), que são rentáveis porém com um pouco mais de complexidade. Projetos com maior complexidade tendem a ser mais demorados e de custo mais alto para a organização.

Por último, são analisados os projetos na região Q1, pouco rentáveis e pouco complexos e os do quadrante Q3, que são os pré-reprovados, em virtude de serem os mais complexos e de menor rentabilidade.

Obviamente, projetos que visam atender a órgãos regulatórios ou governamentais entram como projetos aprovados independente do quadrante na qual estão classificados, mesmo que isso represente alto custo e alta complexidade.

Projetos que não estão ligados aos objetivos estratégicos de cada Setor são descartados inicialmente. Cada Gestor de área tem a oportunidade de defender seu projeto na reunião, a fim de garantir que ele seja realizado.

Realizada a análise dos projetos é então definido o roadmap dos projetos, conforme demonstra o quadro 1:

\begin{tabular}{|c|c|c|c|c|c|c|c|c|c|c|c|c|c|c|}
\hline Projeto & Área & Tempo & JAN & FEV & MAR & ABR & MAI & JUN & JUL & AGO & SET & OUT & NOV & DEZ \\
\hline Projeto D & $\begin{array}{c}\text { Secretaria } \\
\text { Geral }\end{array}$ & $\begin{array}{c}>48 \mathrm{~h} \mathrm{e}<8 \\
\text { semanas }\end{array}$ & $\mathbf{X}$ & $\mathbf{X}$ & & & & & & & & & & \\
\hline Projeto $\mathrm{L}$ & $\begin{array}{c}\text { Central do } \\
\text { Aluno } \\
\end{array}$ & $\begin{array}{c}>8 \text { semanas e }< \\
3 \text { meses }\end{array}$ & $\mathbf{x}$ & $\mathbf{x}$ & $\mathbf{x}$ & & & & & & & & & \\
\hline Projeto $\mathrm{G}$ & $\begin{array}{c}\text { Secretaria } \\
\text { Geral }\end{array}$ & $\begin{array}{c}>8 \text { semanas } \mathrm{e}< \\
\quad 3 \text { meses }\end{array}$ & & & & $\mathbf{X}$ & $\mathbf{X}$ & $\mathbf{X}$ & & & & & & \\
\hline
\end{tabular}




\begin{tabular}{|c|c|c|c|c|c|c|c|c|c|c|c|c|}
\hline Projeto F & $\begin{array}{c}\text { Secretaria } \\
\text { Geral }\end{array}$ & $\begin{array}{c}>48 \mathrm{~h} \mathrm{e}<8 \\
\text { semanas }\end{array}$ & $\mathbf{X}$ & $\mathbf{X}$ & & & & & & & & \\
\hline Projeto A & ProAcad & $\begin{array}{c}>48 \mathrm{~h} \mathrm{e}<8 \\
\text { semanas }\end{array}$ & & & $\mathbf{X}$ & $\mathbf{X}$ & & & & & & \\
\hline Projeto $\mathrm{C}$ & ProAcad & $\begin{array}{c}>3 \text { meses e }<6 \\
\text { meses }\end{array}$ & & & & & $\mathbf{X}$ & $\mathbf{X}$ & $\mathbf{X}$ & $\mathbf{X}$ & $\mathbf{X}$ & $\mathbf{X}$ \\
\hline
\end{tabular}

Quadro 1. Roadmap de Projetos

Durante essa análise, caso algum projeto que entre em conflito de recursos com outro projeto, o Comitê irá decidir por deixar um deles para ser executado em seguida ou pela contratação de recursos externos para atender a demanda.

De comum acordo entre os participantes, é então decretado o final da reunião, com os projetos aprovados pelo Comitê Executivo para realização pelo EGP e equipe de TI.

\section{CONCLUSÕES}

O objetivo desse trabalho foi realizar uma pesquisa exploratória analisando o procedimento seguido pela Universidade privada estudada para alinhar os projetos de TI às estratégias da área de negócio. Este objetivo foi alcançado, uma vez que através dessa pesquisa pudemos concluir a importância do Alinhamento Estratégico no direcionamento dos recursos de $\mathrm{Tl}$, cada vez mais importantes e cada vez mais disputados pelas áreas de negócio como apoio para atingir metas e objetivos estratégicos. Sem um direcionamento adequado, os setores de $\mathrm{Tl}$ das organizações acabam por atender demandas momentâneas e solicitações que não agregam valor ao negócio. $\mathrm{E}$ isto é muito comum de se encontrar em várias organizações no mercado, inclusive do setor educacional.

A implementação de um sistema de gestão que possa alinhar negócio e TI necessita de uma mudança na cultura e mentalidade organizacional, o que pode ser a parte mais delicada e importante de todo o processo, visto que os gestores e todos os envolvidos devem compartilhar este desejo por melhorias e aperfeiçoamento. A visão e a missão bem definidas e disseminadas na organização podem contribuir significativamente para esta questão, pois geram um compromisso e compartilhamento de ideias entre os envolvidos.

A organização estudada mostrou maturidade no uso de ferramentas de gestão, principalmente pelo o uso do BSC, que possibilita, através de seus conceitos e métodos, uma visão clara das estratégias, objetivos e metas empresariais, esclarecendo e estabelecendo consensos. Permite assim uma melhor comunicação e alinhamento de tais objetivos para as necessidades da empresa, verificando onde e como a organização deve agir, focando nos fatores críticos de sucesso como ativos financeiro, intelectuais e intangíveis. Poucas organizações têm a participação do Gestor de TI como membro do Comitê Executivo e como parte integrante das estratégias organizacionais.

O método desenvolvido pelo EGP e pela área de TI da organização estudada facilitou o processo de tomada de decisão pelo Comitê Executivo, oferecendo informações mais consistentes e aproximadas dos projetos a serem realizados.

De acordo com as entrevistas realizadas, o método está em frequente processo de atualização e melhoria. O próximo passo de melhoria é realizar uma análise baseada no método 
AHP (Analytic Hierarchy Process), que ajuda na tomada de decisões complexas e estabelecimento de prioridades junto ao BSC (VERAS, 2013).

Algumas dificuldades foram relatadas pelo EGP durante a captação dos formulários de Requisição de Projetos, uma vez que alguns gestores das áreas demoram bastante para concluir o preenchimento do formulário devido ao detalhamento de informações financeiras e direcionamento de objetivos do projeto. Essa demora retarda a análise e classificação efetuada pelo EGP para fechar os resultados para submissão ao Comitê Executivo.

Esta pesquisa constatou como limitação a impossibilidade de divulgar informações constantes nos formulários e outros documentos. Das informações demonstradas, parte desses dados foi omitida para manter o sigilo das informações institucionais.

Para pesquisas futuras, fica como sugestão a realização de uma nova pesquisa exploratória e outras organizações, com o objetivo de levantar o cenário do uso de para alinhamento estratégico de $\mathrm{TI}$, assim como ferramentas de gestão.

\section{REFERÊNCIAS}

1. ABETTI, P. A. The Impact of Technology on Corporate Strategy and Organization: Illustrative Cases and Lessons. IJTM in Role of Technology in Corporate Policy. New York.

2. BRASIL. Ministério da Educação e Cultura - MEC. Instituto Nacional de Estudos e Pesquisas Educacionais - INEP. Sinopses estatísticas do ensino superior. Brasília, Distrito Federal, 2013. Disponível em <http://portal.inep.gov.br/superior-censosuperior-sinopse>. Acesso em 27/11/2013.

3. BRODBECK, Ângela F.; HOPPEN, Norberto. Alinhamento Estratégico entre os Planos de Negócio e de Tecnologia de Informação: Modelo Operacional para Implementação. In: Anais do 26을 Encontro da ANPAD, Salvador, BA, Brasil. ANPAD: 2003.

4. CERVO, A.L.; BERVIAN, P. Metodologia científica. São Paulo: Prentice Hall, 2003.

5. CRAWFORD, J. K. Improving Organizational Productivity with a Project Office, Contract Management, [S.I.: s.n], v. 40, n. 6, Junho, 2000.

6. EXAME. A corrida dos grupos educacionais pelo Brasil. Abril Cultural, 2013. Disponível em <http://exame.abril.com.br/negocios/noticias/a-corrida-dos-grupos-educacionais-pelobrasil>. Acesso em 21/10/2013.

7. GIL, A.C. Como elaborar projetos de pesquisa. 4. ed. São Paulo: Atlas, 2002.

8. HENDERSON, J. C.; VENKATRAMAN, N. Strategic Alignment: Leveraging information technology for transforming organizations. IBM System Journal, 1993, 32(1), p. 198-220.

9. IBGC - Instituto Brasileiro de Governança Corporativa. Relatório Anual, 2010. Disponível em <http://www.ibgc.org.br/RelatoriosAnuais.aspx>. Acesso em 16/10/2013.

10. IETEC - Instituto de Educação Tecnológica. Evolução de Credenciados PMP, 2008. Disponível em <http://www.ietec.com.br/sites/pmp/credenciados.php>. Acesso em 21/10/2013. 
11. JOHNSON, H. T.; KAPLAN, R. S. Relevance lost - the rise and fall of management accounting. Boston, Harvard Business School Press, 1991.

12. KAPLAN, R. S.; NORTON, D. P. A Estratégia em Ação: Balanced Scorecard, Rio de Janeiro: Campus, 1997.

13. . The balanced scorecard - measures that drive performance. Harvard Business Review, v. 70, n. 1, 71-79, jan/fev 1992.

14. KING, W. R. Strategic Planning for MIS. MIS Quarterly, 1978, 2(1), 27-37.

15. LEDERER, A. L.; SETHI, V. Root Causes of Strategic Information System: Planning Implementation Problems. Journal of MIS, 1992, 9 (1).

16. LUFTMAN, Jerry N.; BRIER, T. Achieving and Sustaining Business - IT Alignment. California Management Review, 1999, 42 (1), 109-122.

17. LUFTMAN, Jerry N. Competing in the information age. New York: Oxford University Press, 1996.

18. MENDONÇA, Claudio Marcio Campos. A influência dos serviços central, complementar e suplementar oferecidos por IES privada na retenção de alunos. Dissertação (Mestrado em Administração) - Pró-Reitoria de Pesquisa e Pós-Graduação. Universidade Potiguar. Natal, 2009.

19. MINTZBERG, H.; AHLSTRAND B.; LAMPEL, J. Safári de Estratégia. Porto Alegre:

20. Bookman, 2000.

21. MINTZBERG, H., QUINN, J. B. O processo da Estratégia. Porto Alegre: Bookman, 2001.

22. PÁDUA, E. M. M. Metodologia de pesquisa: abordagem teóricoprática. Campinas: Papirus, 1997.

23. PMI - Project Management Institute. Disponível em <http://www.pmi.org>. Acesso em 20/10/2013.

24. PORTAL G1. Educação. Após fusão, Kroton e Anhanguera mantêm operações até o aval do Cade, 2013. Disponível em <http://g1.globo.com/educacao/noticia/2013/04/apos-fusaokroton-e-anhanguera-mantem-operacoes-ate-o-aval-do-cade.html>. Acesso em 05/11/2013.

25. RAD, P. F.; RAGHAVAN, A. Establishing an Organizational Project Office. In: AACE International Transactions, 2000

26. REICH, Blaize Horner; BENBASAT, Izak. Measuring the linkage between business and information tecnology objectives. MIS Quartely, 1996.

27. SILVA, Renato. Balanced Scorecard - BSC do Ensino Superior, Paraná: Ed. Juruá, 2009

28. SIM - Society for Information Management. IT Trends Survey, 2011; 2012. Disponível em <http://www.simnet.org/?page=IT_Trends_Survey>. Acesso em 10/10/2013.

29. TRIVIÑOS, A.N.S. Introdução à pesquisa em ciências sociais: a pesquisa qualitativa em educação. São Paulo: Atlas, 1987.

30. YIN, R.K. Estudo de casos: planejamento e métodos. 2.ed. São Paulo: Bookman, 2001. 
31. VERAS, Manoel. Blog Gestão de Projetos, 2013. Disponível em <http://gestaodeprojetos10.blogspot.com.br/2010/06/ahp-analytic-hierarchyprocess.html>. Acesso em 27/11/2013.

1 